\title{
A Case of the Horseshoe Kidney
}

\author{
By
Huayue CHEN, Daisuke HAYAKAWA, Shoichi EMURA*, Yuki OZAWA, Ryuichiro YANO and Shizuko SHOUMURA

Department of Anatomy, Gifu University School of Medicine, Gifu 500-8705, Japan
*Nursing Course, Gifu University School of Medicine, Gifu 500-8807, Japan

- Received for Publication, September 3, 2001 -

Key Words: Horseshoe kidney, Anomaly, Human gross anatomy

\begin{abstract}
Summary: During cadaver dissection for student education in anatomy laboratory of Gifu University School of Medicine, a case of the horseshoe kidney was observed in a 63-year-old Japanese female cadaver. The kidney was fused at the lower poles of the original kidneys by the parenchymatous isthmus and showed a typical horseshoe shape. The hili on both sides opened towards the ventral direction, and the ureters descended in front of the isthmus and entered the bladder normally. The location of the kidney was lower than that of the normal kidney. Four surplus arteries entered the isthmus and the lower part of the kidney besides the normal right and left renal arteries. The incidence of the horseshoe kidney during the dissecting practice at Gifu University School of Medicine from 1971 to 1997 was estimated to be $0.36 \%$ ( 4 out of 1130 bodies).
\end{abstract}

The horseshoe kidney is a well-known congenital fusion anomaly of the kidney. There have been many reports on this anomaly in Japan. The horseshoe kidney is clinically diagnosed by pyelography. Horseshoe kidney occurs in about $0.25 \%$ of the population and it is found more commonly in males by a 2:1 margin (Walsh et al., 1998; Basar et al., 1999). During dissecting practice at Gifu University School of Medicine, we encountered a case of horseshoe kidney in a 63-year-old Japanese female cadaver who died of uterine cancer. This paper describes the anatomical findings of the horseshoe kidney as the reference data on this kind of anomaly.

\section{Observations}

\section{Shape, Size and Position of the Kidney}

The right and left kidneys fused at their lower poles by the isthmus, which located at the ventral side of the abdominal aorta and the inferior vena cava (Fig. 1). The size of the left kidney was slightly larger than that of the right kidney. The left kidney measured $116 \mathrm{~mm}$ in length, $47 \mathrm{~mm}$ in width, and
$42 \mathrm{~mm}$ in thickness, against $110 \mathrm{~mm}$ in length, $41 \mathrm{~mm}$ in width, and $39 \mathrm{~mm}$ in thickness in the right kidney. The isthmus was $47 \mathrm{~mm}$ in length, $23 \mathrm{~mm}$ in width, and $19 \mathrm{~mm}$ in thickness at the central portion. The upper pole of the left kidney was at the level of upper border of the 1st lumbar vertebra, and that of the right was at the level of lower border of the 1st lumbar vertebra. The lower poles of the left and right kidneys were similar, at the level of lower border of the 4th vertebra. The isthmus located between the lower border of the 3rd and 4th lumbar vertebrae. A marked sulcus formed by the abdominal aorta was found at the dorsal side of the isthmus. Light microscopy showed that the isthmus was almost the same as the other parts of the original kidneys, containing convoluted tubules and glomeruli.

\section{Renal Hilus, Pelvis and Ureter}

The hilus of the kidney opened largely in the ventral direction (Fig. 1). The left hilus was $50 \mathrm{~mm}$ in length by $23 \mathrm{~mm}$ in width. The right one was $78 \mathrm{~mm}$ in length by $20 \mathrm{~mm}$ in width. The left and right pelves consisted of 3 and 5 major calyces respectively. The length of the left ureter was little

Correspondence to: Huayue Chen, Department of Anatomy, Gifu University School of Medicine, 40 Tsukasa-machi, Gifu 500-8705, Japan. 


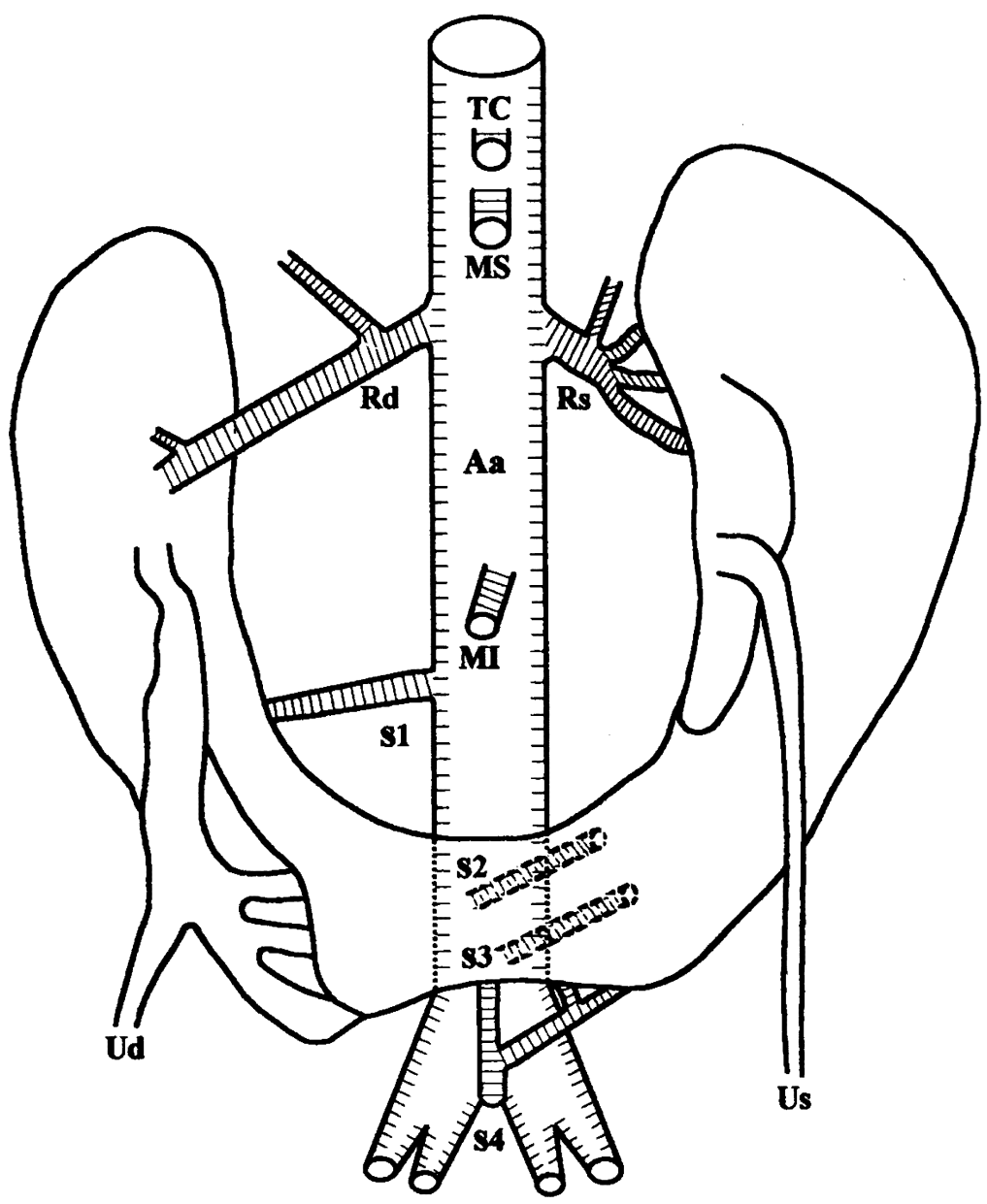

Fig. 1. Schematic illustration of the arterial supply of the horseshoe kidney.

Aa: Aorta abdominalis; MI: A. mesenterica inferior; MS: A. mesenterica superior; Rd: A. renalis dextra; Rs: A. renalis sinistra; $s 1 \sim 4$ : surplus arteries; TC: Truncus celiacus; Ud: Ureter dexter; Us: Ureter sinister.

longer than that of the right one. Both ureters originated from the pelves and ran downwards obliquely on the ventral surface of the kidneys reaching the bladder normally.

\section{Blood Vessels}

The left renal artery with the diameter of $5.3 \mathrm{~mm}$ arose directly from the left side of the abdominal aorta at the lower border of the 1st lumbar vertebra. It entered the renal hilus after sending off the left inferior suprarenal artery. The right renal artery with the diameter of $3.8 \mathrm{~mm}$ entered the upper part of the right kidney. Four surplus arteries entered into the horseshoe kidney besides the normal right and left renal arteries (Fig. 1). Three surplus arteries directly arose from the abdominal aorta, entered the isthmus and the lower part of the right kidney. The median sacral artery was absent in normal position, instead, one surplus artery, which was the terminal branch of the abdominal aorta, with a diameter of $3.3 \mathrm{~mm}$, ascended in front of the abdominal aorta and divided into 3 branches supplying the isthmus and lower part of the left kidney. The renal veins were found to leave the renal hilus and entered the inferior vena cava. The left renal vein, after receiving the left suprarenal and ovarian veins, entered the inferior vena cava. There were two renal veins on the right side, which entered the inferior vena cava separately. Another vein emerged from the ventral portion of the isthmus and joined the inferior vena cava directly.

\section{Discussion}

The horseshoe kidney is probably the most common of all renal anomalies. According to Moore (1977), the development of human renal anlage 
begins around the 4th week of the embryonal life. In the fifth week, the ureteric bud begins to ascend towards the lumbar region with internal rotation. The rotation is completed around the 8 th week of embryonic development. Thus, the kidney normally ascends to the lumbar region from their initial position in the pelvis, and the kidneys pass through the arterial fork formed by the umbilical arteries during the ascent. During their passage through the arterial fork, both kidneys are sometimes so close that their lower poles fuse (Moore, 1977).

As to the time of the development of the horseshoe kidney, various hypotheses have been proposed. In most cases, the hilus is abnormally rotated ventrally and this phenomenon represents one of the reasons for assuming that the fusion probably takes place prior to or in the very beginning of the 5th week of the embryonal life, when the rotation begins (Moore, 1977; Walsh et al., 1998).

As to the cause of the fusion of the kidneys, Doménech-Mateu and Gonzalez-Compta (1988) proposed a new theory on the embryogenesis of the horseshoe kidney based on the study of human embryo. The isthmus of the horseshoe kidney was formed by cells from the posterior nephrogenic area of the epiblast, those which for an incomplete or abnormal migration across the primitive streak remain in the midline forming the isthmus of the horseshoe kidney. The isthmus is generally bulky and consists of parenchymatous tissue with its own blood supply (Walsh et al., 1998). Tanuma et al. (1982) found that the isthmus of the horseshoe kidney contained more convoluted tubules, connective tissues and fewer glomeruli as compared with other parts of the kidney. In the present case, we found that the histological finding of the isthmus was almost the same as the original kidneys. The border between the original kidneys and the isthmus was unclear.

Among the cases of horseshoe kidney reported in Japan, surplus arteries derived from the abdominal aorta, inferior mesenteric artery and common iliac artery were observed in many cases (Matuo, 1944; Isomura et al., 1988; Nagashima et al., 1990; Kosugi et al., 1991; Shoumura et al., 1992). Artery arising from the abdominal aorta a little above its bifurcation, with no median sacral artery was found by Fuyuta (1977). In the present case, the normally descending median sacral artery was absent. Instead, the artery probably corresponding to this ascended and distributed over the isthmus and lower part of the left kidney. It indicated that the fusion occurred before the ascent of the renal anlage to the lumbar region from the pelvis.

Sekine et al. reported (1990) a case of the horse- shoe kidney with almost normal position of the kidney. However, in most cases, the position of the horseshoe kidney is described as being lower than that of the normal kidney, which is considered to be one of the striking characteristics of the horseshoe kidney (Takeshige et al., 1966; Fuyuta et al., 1977; Ohkubo et al., 1981). This is because the inferior mesenteric artery presents the isthmus from allowing ascent of the kidney, with a consequent pressure groove developing on the surface of the kidney (Kitagawa et al., 1979). In the present case, the position of the kidney was clearly lower than the normal. There was some distance from the origin of the inferior mesenteric artery to the upper border of the isthmus. We consider that not only the inferior mesenteric artery, the surplus arteries also can restrict the normal ascending of the kidney.

The horseshoe kidney is a relatively frequent malformation. In the literature, it occurred in 0.20 $0.48 \%$ of the population (Shoumura et al., 1992; Walsh et al., 1998; Basar et al., 1999). It was found more commonly in males by a $2: 1$ margin (Walsh $e t$ al., 1998). Basar et al. (1999) applied on 6985 urologic patients and 2680 autopsy cases and found the horseshoe kidneys in 23 of patients and in 6 of autopsy cases in Turkey. The incidence of the horseshoe kidney was $0.33 \%$ and $0.22 \%$ respectively. The ratio of the male/female was $2.6 / 1$. It is difficult to determine the accurate number of horseshoe kidney in Japan. We conjecture that there are 101 cases of horseshoe kidney since Imada's report (1890). The number of male and female cadaver is 60 and 26 respectively. The gender of 15 cadavers is obscure. The ratio of male to female is $2.3: 1$. We found 4 cases of horseshoe kidney among 1130 cadavers from 1971 to 1997 in Gifu University School of Medicine. The incidence is $0.36 \%$.

\section{References}

1) Basar H, Basar R, Basar MM and Erbil M. The comparison of the incidence of horseshoe kidney in autopsy cases versus urologic patient population. Okajimas Folia Anat Jpn 1999; 76:137-140.

2) Doménech-Mateu JM and Gonzalez-Compta X. Horseshoe kidney: a new theory on its embryogenesis based on the study of a 16-mm human embryo. Anat Rec 1988: 222:408 417.

3) Fuyuta M, Ukeshima A and Miyayama Y. An autopsy case of horseshoe kidney. Okajimas Folia Anat Jpn 1977; 53:323-336.

4) Imada T. A case of the horseshoe kidney. Chugai Med J 1890; 204:953-956 (in Japanese).

5) Isomura $G$, Kubo $K$ and Uematsu $H$. Ramified pelves and their blood supply of the horseshoe kidney in 2 Japanese. Anat Anz 1988; 167:393-402.

6) Kitagawa T, Takeuchi K, Kimura S, Muramatsu $H$ and Shimada K. One case of the horseshoe kidney. Acta Anat 
Nippon 1979; 54:93-98 (in Japanese).

7) Kosugi K, Koda M, Kageyama I, Fukushima O, Takeuchi $\mathrm{S}$, Hayakawa T, Kato $\mathrm{S}$ and Yamashita $\mathrm{H}$. Horseshoe kidney - a case report. Jikeikai Med J 1991; 38:143-149.

8) Matuo $\mathrm{H}$. One case of the horseshoe kidney. Acta Anat Nippon 1944; 22:130-136 (in Japanese).

9) Moore KL. The developing human: clinically oriented embryology, 2nd Ed, 220-224, W.B. Saunders Co., Philadelphia, 1977.

10) Nagashima S, Tanaka I, Yamaki K, Hiromatsu S, Hiranuma S, Naruse I, Yoshihara M and Miyazaki M. A case of the horseshoe kidney. J Kurume Med Assoc 1990; 53:1046-1053 (in Japanese).

11) Ohkubo $M$, Ichikawa $S$, Odajima $G$ and Uchino $S$. An autopsy case of horseshoe kidney. Okajimas Folia Anat Jpn 1981; 57:337-346.

12) Sekine G, Ohmori T, Kodama $J$ and Toh H. Horseshoe kidney found in a female cadaver. Okajimas Folia Anat Jpn 1990; 66:365-374.

13) Shoumura S, Emura S, Utsumi M, Chen H, Hayakawa D, Yamahira T, Tamada A, Terasawa K, Aoki T, Sato K and Isono $\mathrm{H}$. Two cases of the horseshoe kidney. Acta Anat Nippon 1992; 67:226-229 (in Japanese).

14) Takeshige $Y$, Takaoka $C$, Yasunari $T$ and Abiru M. A case of the horseshoe kidney. J Kurume Med Assoc 1966; 29:540-549 (in' Japanese).

15) Tanuma K, Asakawa M, Ogura K, Kitazawa M, Shimizu Y, Ogura $S$ and Kikkawa $F$. The horseshoe kidney and consideration of its formation. J Nippon Med Sch 1982; 49:123-129 (in Japanese).

17) Walsh PC, Retik AB, Vaughan ED Jr and Wein AJ. Campbell's Urology, 7th Ed. Bauer SB, Anomalies of the kidney and ureteropelvic junction. 1708-1756, W.B. Saunders Co., Philadelphia, 1998. 